\title{
Trabalhadores da Albras e sua organização política*
}

Vera Lúcia Batista Gomes - Profesora do curso de Serviço Social do Centro SócioEconômico da Universidade Federal do Pará (CSE-UFPA)

Edna Ramos de Castro - Professora do Núcleo de Altos Estudos Amazônicos da Universidade Federal do Pará (NAEA-UFPA)

\section{Resumo}

As formas organizativas de trabalho nas empresas vêm sofrendo profundas mudanças durante o final do século XX e início do século XXI, dificultando a luta em torno dos interesses dos trabalhadores e da sociedade em geral. Neste contexto, o objetivo deste estudo é analisar as particularidades da situação atual na organização política dos trabalhadores da Albras, a partir das transformações ocorridas nesta empresa, e de que forma repercute no Sindicato dos Trabalhadores nas Indústrias Metalúrgicas do Estado do Pará-SIMETAL. Deste modo, pretende-se compreender os desafios postos para a ação coletiva dos trabalhadores diante de uma nova reestruturação dentro do capitalismo industrial.

\section{Abstract}

As of the late $20^{\text {th }}$ century and beginning of the $21^{\text {st }}$ century, workers organizations have deeply changed. Workers struggle to defend their interests and those of the society in general have become more and more difficult. This study analyzes the particularities of the present status of Albras workers political organization, based on the changes undergone by the company, and how those changes affected the Metal Industry Workers Union of the State of Pará (SIMETAL). It tries to understand the challenges to the workers collective actions towards a new structure within the industrial capitalism.

\section{Palavras-chave}

Trabalhadores, organização política, Albras.

\section{Keywords}

Workers, political organization, Albras.

* A elaboração deste artigo contou com o apoio do CNPq. 


\section{INTRODUÇÃO}

Nas últimas décadas do século $\mathrm{XX}$, a organização do trabalho começou a sofrer profundas transformações, tanto nas empresas, como nas instituições públicas e privadas. Pesquisas e debates têm sido feitos para elucidar os impactos dessas transformações sobre os trabalhadores, seja com relação à sua vida no trabalho, seja em relação às formas organizativas, como os sindicatos.

Em nenhuma outra conjuntura recente, em escala mundial, e em particular na América Latina e no Brasil, os sindicatos enfrentaram tantos desafios. Constata-se, por exemplo, atualmente uma diminuição das taxas de sindicalização e do poder de negociação dos interesses coletivos dos trabalhadores. Cabe, portanto, tentar descobrir os novos rumos que os sindicatos devem tomar.

Nesse sentido, são expressivas as análises de Lowy (1999), para quem o movimento operário atravessa uma grave crise, que afeta o conjunto de suas organizações sindicais e políticas. Para esse autor, tratase de uma crise de um modelo específico, o modelo socialdemocrata, nascido no fim do século XIX, cujas principais variantes são a socialdemocracia em sentito estrito e o leninismo.

Sendo assim, no momento atual do capitalismo, o movimento operário defronta-se com dificuldades que o forçam a encontrar novas formas de organização e ação.

De acordo com as análises de Rodrigues (apud RAMALHO, 1997) sobre o sindicalismo em países cujas organizações dos trabalhadores pareciam consolidadas, as dificuldades enfrentadas por esses sindicatos dever-se-iam à globalização da economia, ao acirramento da competição internacional, às pressões por maior rapidez nas tomadas de decisão e por uma maior flexibilidade nas formas de organização do trabalho, o que levaria as empresas a buscar modalidades de relacionamento com os trabalhadores que não passam pelo sindicato. Esse autor acrescenta ainda a esses fatores a terceirização, o aumento da proporção dos empregados em tempo parcial, a participação cada vez maior na força de trabalho de mulheres e de jovens que não têm perspectivas de continuidade na empresa ou no setor de atividades.

No Brasil, dentre outros estudos sobre o sindicalismo como organização política dos trabalhadores, destacam-se os efetuados por Ramalho (1997), os quais indicam que o movimento sindical brasileiro conseguiu um lugar de proeminência no cenário político e econômico nos últimos anos. Contudo, enfrenta a crise provocada pela restruturação 
com um certo poder de barganha, obtido por meio daslutas e greves deum passado recente, tendo ainda um surpreendente poder de pressão para negociar alternativas para as atuais formas de desenvolvimento econômico e apoiar projetos políticos que visam diminuir as desigualdades no país. Para esse autor, as análises realizadas nos vários segmentos das indústrias brasileiras apontam uma variação na ação sindical efetiva: nos setores mais modernos, há uma ação sindical efetiva, que os obriga ao encaminhamento de novas formas de gestão por meio da negociação; entretanto, na maioria dos outros setores, verifica-se um processo gradativo de precarização coletiva dos trabalhores.

Os estudos acima referidos acerca da organização política de trabalhadores - mais especificamente, sobre os sindicatos - constatam que, no mundo inteiro, essas organizações, sobretudo nas últimas décadas, têm tido dificuldades para impedir a destituição de direitos e para lutar pelos interesses dos trabalhadores e da sociedade como um todo. De uma maneira geral, os referidos estudos tendem a relacionar as dificuldades encontradas pelos sindicatos com as profundas transformações que têm ocorrido na organização de trabalho das empresas, no final do século XX e no início do século XXI.

Se é verdade que as mudanças na organização de trabalho têm dificultado as lutas das organizações políticas dos trabalhadores em geral, deve-se tentar examinar a situação dos trabalhadores no Estado do Pará. Assim, pergunta-se: qual é a situação atual da organização política dos trabalhadores da Albras ${ }^{1}$ em relação a essas mudanças? Quais as particularidades dessas mudanças na Albras e de que forma elas têm repercutido no Sindicato dos Trabalhadores nas Indústrias Metalúrgicas do Estado do Pará (SIMETAL), que até então representa a maior organização política desses trabalhadores? O objetivo deste trabalho é analisar a especificidade da situação atual da organização política dos trabalhadores da referida empresa, tendo por base as transformações na organização de trabalho, e tentar verificar até que

\footnotetext{
${ }^{1}$ A Albras é uma empresa integrante da Companhia Vale do Rio Doce (CVRD), a qual é caudatária da implantação dos Grandes Projetos na Amazônia, entre os quais o Programa Grande Carajás (PGC). A CVRD, por ser a maior empresa mundial de ferro, foi escolhida pelo governo brasileiro para explorar sistematicamente as riquezas naturais na região, visando gerar divisas para o país e superar o período crítico decorrente da crise mundial. A implantação da Albras na Amazônia deu-se em 1985, objetivando a produção do alumínio primário voltada para a exportação. A empresa é composta de capital binacioal (japonês x brasileiro): a CVRD participa com 51\% e a acionária Nippon Amazon Aluminium Copany (NAAC), com 49\%. A Albras é considerada a maior fábrica de alumínio do continente e a maior indústria do Pará. Sobre a Albras, maiores informações ler Lôbo (1996), Becker (1994), entre outros.
} 
ponto essas transformações têm influído nessa organização política no que diz respeito à luta pelos interesses coletivos desses trabalhores.

Para tanto, pretende-se inicialmente focalizar as principais mudanças na organização de trabalho ocorridas na Albras nas últimas décadas e a partir daí analisar as suas implicações para o Simetal, enquanto força política dos trabalhadores da referida empresa, bem como analisar os desafios enfrentados por essa organização na luta em defesa dos interesses dos trabalhadores e da sociedade em geral.

Dessa maneira, o texto apresenta-se dividido em três partes. Na primeira, procura-se analisar as principais mudanças na organização de trabalho da Albras. Na segunda, busca-se analisar as implicações dessas mudanças para o Simetal, bem como as estratégias até então utilizadas por essa organização política de trabalhadores na luta em defesa de seus interesses. Na terceira e última, pretende-se tecer algumas considerações críticas sobre tais estratégias, finalizando com a indicação de possíveis alternativas para enfrentar esse momento histórico, que parece apontar novos rumos para a organização dos trabalhadores no sentido de preparar a construção de um caminho inverso ao do individualismo dos trabalhadores, caminho próprio do neoliberalismo.

\section{1- A ORGANIZAÇÃO DO TRABALHO E A ALBRAS}

Para tratar das mudanças na organização do trabalho na Albras, é preciso inicialmente explicitar o que se entende por organização de trabalho, bem como os fatores que têm provocado essas mudanças. A partir daí, tentar-se-á compreender o conteúdo e a forma dessas mudanças e suas implicações para a organização política dos trabalhadores dessa empresa: o Simetal.

A organização de trabalho diz respeito à divisão e à repartição do trabalho entre os trabalhadores, envolvendo, assim, o conteúdo da tarefa e as relações humanas de trabalho (CHRISTOPHE, 1994). Nessa concepção de organização de trabalho, é fundamental a noção de divisão do trabalho, categoria-chave para as referidas mudanças na organização do trabalho que têm ocorrido na mencionada empresa.

Segundo Coutrot (1999), o progresso da civilização, a eficácia econômica e a coesão social repousam na divisão do trabalho. Tal entendimento é comum na economia e na sociologia clássica. Para Adam Smith (1982), por exemplo, o declínio do trabalho do artesão deveu-se à ascensão de numerosas tarefas parcelares, asseguradas por cada trabalhador especializado, o que permitiu ganhos fantásticos de produção. Desse modo,a divisão do trabalho é necesssária à produção 
das mercadorias, pois é o trabalho que detemina os valores de troca. As grandes melhoras no potencial produtivo do trabalho e a maior parte das habilidades e da inteligência com as quais se realiza o trabalho devem-se à divisão do trabalho. Com essas considerações, Smith anuncia as vantagens da divisão do trabalho, afirmando que é dela e da relação entre chefias e trabalhadores que surge a modernidade das novas relações que determinam a economia de mercado e, mais ainda, o capitalismo.

A importância da divisão do trabalho para a sociedade encontrase explícita em Émile Durkheim (1978). Para ele, as antigas formas de solidariedade entre as vizinhanças ou os clãs, consideradas como solidariedade mecânica, foram substituídas por uma nova forma de laço social: a solidariedade orgânica, que é resultante da interdependência dos agentes econômicos graças à divisão do trabalho (COUTROT, 1999).

Em Marx (1989), a divisão do trabalho abrange desde a separação entre as profissões mais diferentes possíveis, até a divisão em que os diversos trabalhadores dividem entre si a elaboração de um único produto, como na manufatura. Assim, a divisão do trabalho e a correspondente limitação dos indivíduos a esferas profissionais particulares são tributárias da divisão do trabalho na manufatura, pois, anteriormente a esse estágio de produção, na família e na tribo, havia uma divisão natural do trabalho em virtude das diferenças de sexo e idade, isto é, a divisão de trabalho era puramente fisológica.

Contudo, com o crescimento da população e notadamente com o conflito entre as diversas tribos e a subjugação de uma à outra, essa divisão foi se ampliando. Desse modo, o fundamento de toda divisão do trabalho é a mercadoria: do campo à cidade, da manufatura à grande indústria. Esta última é considerada por Marx a mais extensa divisão do trabalho, porque universalizou a concorrência, estabeleceu os meios de comunicação e o mercado mundial moderno. O comércio transformou todo o capital em capital industrial e provocou assim a rápida circulação (desenvolvimento de finanças) e a concentração dos capitais. A concorrência universal aniquilou certas ideologias, religiões e valores morais, criando assim, pela primeira vez, a história universal, na medida em que tornou dependente todo o mundo de todas as nações civilizadas e todos os indivíduos nelas existentes para a satisfação das suas necessidades, subordinou ao capital a ciência da natureza e retirou da divisão do trabalho a última aparência de naturalidade (MARX; ENGELS, 1984). 
Segundo Marx, a divisão do trabalho provoca as contradições sociais, uma vez que as forças produtivas não podem ser aplicadas na propriedade privada, deste modo a grande indústria não atinge o mesmo nível de desenvolvimento em todas as localidades de um país.

Contudo, é com o surgimento da grande indústria, sustentada pelas idéias revolucionárias da época, que começa a dissolução das antigas formas produtivas, características do feudalismo, e a formação de uma mentalidade empresarial moderna, cuja organização do trabalho passa a ser baseada na previsão, no cálculo e em técnicas racionais de contabilidade. Isso torna possível a administração racional da empresa, formando-se assim as bases para a emergência de uma força de trabalho formalmente "livre", o que facilitou a constituição do trabalho assalariado e, com isso, o começo da organização política dos trabalhadores assalariados.

Ao mesmo tempo, as empresas passaram a preocupar-se mais em adotar estratégias para conservar e ampliar a riqueza que produziam: surge a Administração Científica do trabalho. Taylor, ao incorporar essa grande tarefa, propôs a "organização racional do trabalho", que, além de permitir ganhos cada vez maiores de produção, permitia também o controle e a disciplina dos trabalhadores.

Tal organização do trabalho significou um novo padrão de acumulação, que intensificava o trabalho para elevar a produção do capital. Em conseqüência, houve aumento do desemprego, diminuição dos salários, bem como a desqualificação de profissões por meio de uma nova recomposição entre "trabalho vivo" e "trabalho morto", ou seja, cada trabalhador passaria a gerir máquinas e ferramentas desenhadas e organizadas com o objetivo de serem mais produtivos, e a extração da mais-valia relativa seria, portanto, muito mais elevada.

A forte reação dos trabalhadores a essa forma de organização de trabalho levou Taylor a formular estratégias de "cooperação" entre o capital e o trabalho. Como o capital e o trabalho opõem-se, houve uma resposta política dos trabalhadores, como as greves nos Estados Unidos, particularmente em Nova York, que se constituíram no maior movimento de protestos da época e culminaram com a organização das trades unions, em 1. ${ }^{\circ}$ de maio de 1886 (Chicago). A bandeira de luta dessa organização era a jornada de 8 (oito) horas de trabalho.

Fatos dessa natureza representaram um entrave à organização taylorista, dado o ritmo exigido pela produção em série, o que de certa forma impulsionou o desenvolvimento de máquinas-ferramentas de manejo mais simplificado, possibilitando a incorporação de uma massa de trabalhadores não especializados. A organização científica do trabalho 
introduziu, então, os princípios da padronização (entre outros), cujo eixo era a divisão do trabalho: o operário, ao acostumar-se a realizar apenas uma parte do todo (tarefa), tornava-se um especialista, e o resultado esperado era o aumento da produtividade, pela possibilidade de padronizar o tempo de produção, o que resultava em maior qualidade do produto ou serviço e maior redução de custos.

Para garantir o aumento da produtividade, a divisão do trabalho estabeleceu formas de controle dos trabalhadores não só no que diz respeito ao ato criativo inerente a qualquer ser humano, mas também quanto ao aspecto político, visto que fragmenta os trabalhadores, gerando um "fosso" entre o empregado precário, desqualificado, do "chão de fábrica" e os trabalhadores qualificados, ou seja, técnicos e engenheiros, separando, assim, criadores e executantes.

Os significativos ganhos de produtividade obtidos com essa organização de trabalho incentivaram os sindicatos de trabalhadores a reivindicar ganhos de produtividade, decorrendo daí um novo compromisso entre o capital e o trabalho: o pacto fordista, recusado inicialmente por quase todos os patrões da época, exceto alguns patrões (Henri Ford), banqueiros e homens políticos (Keynes), que haviam percebido que a aceleração dos ganhos de produtividade levaria a uma gigantesca crise de superprodução se não houvesse uma revolução paralela do lado da demanda, o que se daria por meio do aumento do poder aquisitivo dos próprios trabalhadores.

O incontornável problema da demanda social, provocado pela concorrência entre as empresas, fez surgir três alternativas ao conservantismo liberal daquele momento, as quais foram utilizadas por teóricos, políticos e sindicalistas: o fascismo e stalinismo, que propunham a organização estatal da demanda, com sérias divergências quanto a sua orientação, e a socialdemocracia, versão "de esquerda" da proposta "de direita" de Keynes e Ford - "um compromisso global e organizado entre o patronato e o sindicato, que permitisse a redistribuição dos ganhos de produtividade aos assalariados" (LIPIETZ, 1991, p. 31).

Para Lipietz (1991), a derrota do fascismo e o confronto entre o stalinismo e o capitalismo, durante a Segunda Guerra Mundial, em menos de dez anos, possibilitou a evolução do compromisso fordista, o qual se materializou em um regime de acumulação e um modo de regulação. Esse compromisso implicava a ligação entre a produção em massa crescente e o consumo da massa crescente, sendo considerado pelo mundo

\footnotetext{
${ }^{2}$ Para maiores detalhes sobre os impedimentos do fordismo nos anos entre guerras, ver Harvey (1995).
} 
inteiro, após a Segunda Guerra Mundial, como o american way of life. Tal modelo foi implantado no Brasil, onde se chamou "substituição de importações". Inspirava-se no modelo americano de industrialização, cuja base de sustentação era formada pela indústria de bens duráveis e pelo consumo de massa. Contudo, no Brasil, tal modelo assumiu um caráter fortemente excludente, porquanto incorporou segmentos relativamente reduzidos ao mercado de trabalho organizado e criou um mercado extremamente selecionado e restrito. Esse modelo caracterizou-se essencialmente pela concentração de renda com base quase exclusivamente na coerção, quer por meio do Estado, quer por meio da gestão da força de trabalho pelo capital, visto que os trabalhadores foram submetidos ao novo padrão de vida proporcionado pelo desenvolvimento industrial.

Desse modo, no Brasil, o fordismo assumiu uma forma diferente da dos demais países centrais, no que diz respeito às relações políticas. Com efeito, houve negociação com os sindicatos de trabalhadores, o que permitiu a incorporação da representação sindical e a sua adesão às normas fordistas, o que foi fundamental para neutralizar as resistências ao compromisso fordista. Além disso, no Brasil não existe o Estado de Bem-Estar Social, como nos referidos países centrais, o que decerto reforçou ainda mais o caráter excludente da indústria brasileira, bem como reproduziu um mercado de trabalho desorganizado, estruturalmente informalizado, sem garantias institucionais para grande parte da sociedade. Enfim, produziu-se um "Estado de Mal-Estar Social", segundo Francisco de Oliveira (1984).

Não havendo políticas sociais efetivas geridas pelo Estado, voltadas para a reprodução social da força de trabalho, criou-se um verdadeiro welfare state nas empresas (MOTA, 1991 apud BORGES; DRUCK, 1993): políticas sociais de gestão empresarial que transcendem os muros do espaço fabril, por meio da institucionalização de um conjunto de benefícios sociais - salários indiretos - a fim de garantir determinado padrão de consumo dos empregados e, conseqüentemente, a sua reprodução social. Ressalte-se que esse welfare state limitava-se a empresas de médio e grande porte, isto é, àqueles setores do capital que são reconhecidamente estratégicos para o padrão de desenvolvimento brasileiro.

Desse modo, são beneficiados por essas políticas sociais privadas, apenas, uma parcela dos trabalhadores incluídos no mercado formal de trabalho, constituído por aqueles que têm uma relação de trabalho institucionalizada. 
As particularidades do fordismo no Brasil tornam-se mais explicítas quando se analisa o quadro político, o qual foi marcado por um autoritarismo que impregnou as instituições políticas e a sociedade civil, visto que a democracia não consolidada fragilizou a luta dos trabalhadores e afetou a constituição de suas organizações. Com efeito, a organização política dos trabalhadores fez-se por meio da estrutura sindical brasileira que se ergueu após a década de 30 do século XX, inserida no modelo de industrialização adotado, expresso significativamente num Estado-antidemocrático, na medida em que havia o atrelamento dos sindicatos ao Estado e a intervenção estatal policialesca nos movimentos sociais. Sendo assim, é fundamentalmente pela força do Estado e pelas "políticas sociais empresariais" nas empresas que se definem os espaços de atuação e "participação dos trabalhadores" (BORGES; DRUCK,1993).

Nesse contexto, a posição do movimento sindical fordista era defensiva, porém sem estratégias políticas mais globais e menos individualizadas em suas lutas e reivindicações e sem uma base fabril mais consolidada dos sindicatos. Esses fatos contribuíram para a manutenção do fordismo periférico no Brasil, que para Lipietz (apud LIMA, 1995) foi apenas uma caricatura de fordismo, constituindo tãosomente uma tentativa de industrialização de acordo com a tecnologia e o padrão de consumo fordiano, mas sem as condições sociais, nem do lado do processo de trabalo, nem do lado do padrão de consumo de massa.

Segundo Lima (1995), nos países periféricos, não houve a ampliação do mercado consumidor em decorrência não só da ausência de uma política salarial, mas também dos baixos salários. De fato, não foi respeitada uma das premissas básicas do fordismo, que é o consumo intensivo de bens e serviços. Entretanto, contraditoriamente, um dos fatores que contribuíram para a transferência desse processo produtivo para os países periféricos foram os baixos salários: o aumento salarialque esultou da instalação do padrão fordista periférico não gerou os efeitos esperados no mercado consumidor, pois ficou restrito a uma determinada classe de renda.

Considerando a organização de trabalho do fordismo periférico, que exigia tecnologia e mão-de-obra especializada, Lima (1995) fala da presença dos "enclaves de fordismos periféricos" no Brasil, particularmente no Estado do Pará, em determinados ramos de produção, como exploração da hematita, do alumínio, da bauxita, da pasta química de madeira, do manganês, do caulim e do ferro-gusa, responsáveis por 
80\% (1989) das exportações paraenses. Essa organização de trabalho exigia tecnologia e mão-de-obra especializada, o que não seria possível no Pará, pelo nível de qualificação da força de trabalho e da qualidade de vida exigida nesses projetos; porém, o fato de a história de ocupação do Pará estar definitivamente ligada ao contexto mundial constituiu um fator facilitador para tal. Apesar disso, o fordismo periférico não se estendeu ao restante da economia regional. Com efeito, embora não existam estudos que abordem o conjunto da socioeconomia regional na ótica da teoria da regulação, pode-se afirmar que não há nem mesmo o fordismo periférico, dado o atraso tecnológico, a arcaica organização do trabalho e o baixo nível de consumo, características da economia tradicional. O modelo fordismo ficou, então, restrito a determinadas áreas. Assim, na Amazônia, métodos arcaicos convivem com modernas técnicas de produção (fordismo): destacam-se, por exemplo, na Amazônia Ocidental, as empresas industriais instaladas na órbita da Superintendência da Zona Franca de Manaus; na Amazônia Oriental, sobressaem os grandes projetos minerometalúrgicos e energéticos (LIMA, 1995).

Conforme sugere Lipietz, para compreender a organização de trabalho na Albras, é preciso ter como referência o fordismo periférico, por causa das características da empresa na região no que tange à qualificação profissional, aos salários - que, em geral, estão acima da média regional - e ao padrão de vida - mais elevado, em virtude dos benefícios sociais oferecidos pela empresa -, o que contribui para a formação de uma "elite trabalhadora" e para o aumento das disparidades sociais na região.

\subsection{A organização de trabalho fordista na Albras}

Para tratar da organização de trabalho fordista na Albras, é preciso tecer considerações sobre o processo produtivo da empresa, ainda que de forma muito breve.

A produção do alumínio primário na Albras inicia-se com o beneficiamento da bauxita (minério do alumínio), o qual é realizado pela empresa Alumínio do Norte (Alunorte); após o beneficiamento, o minério é transportado para a Albras, onde é fabricado o produto final, que é o lingote. Para tal, a Albras adotou inicialmente a mesma tecnologia utilizada pela empresa Mitsui Aluminiun Co. Ind., do Japão, para os

\footnotetext{
${ }^{3}$ A bauxita é produzida pela empresa Mineração Rio do Norte (MRN), cujas jazidas localizam-se no município de Oriximiná-Pará/Porto Trombetas, distante aproximadamente $800 \mathrm{~km}$ de Belém e 440 km de Manaus. Essa empresa é integrante do PGC e foi inaugurada em 1979.
} 
fornos pré-cozidos, além de uma organização de trabalho dividida entre a área de produção e a área administrativa. A área de produção é composta da área de carbono e da área de redução e fundição, as quais dispõem do suporte logístico da área de serviços industriais (serviço de manutenção e reparo dos equipamentos e da fábrica como um todo). A área administrativa abrange a gestão de pessoas, a comunicação e a área comercial e financeira.

O processo produtivo tem início na área de carbono por meio da divisão de anodo verde I e II e da divisão de chumbamento, onde ocorre a decomposição da alumina em alumínio e oxigênio. O alumínio é transferido em cadinhos para os fornos de espera.

Para a operacionalização do processo produtivo, a Albras, na sua fase inicial de implantação, recrutou para o seu quadro técnico profissional mão-de-obra de vários Estados brasileiros, sobretudo do Estado do Pará e do Estado de Minas Gerais. A mão-de-obra mais especializada, como os engenheiros metalúrgicos, é, em geral, originária do Estado de Minas Gerais, que possui uma tradição na indústria do alumínio. Essa tradição não existe na Amazônia: na região, a Albras é a primeira indústria do ramo. Porém, a maioria dos trabalhadores da empresa é oriunda do Estado do Pará. Este fato pode estar relacionado com a lógica da criação do projeto Albras: como integrante do PGC, a empresa visa o progresso e o desenvolvimento da região, por meio do aproveitamento dos recursos naturais. O objetivo maior é a geração de divisas para o país a fim de combater a crise econômica. A contratação de mão-de-obra paraense deve-se também às conquistas do Simetal, que assinou um acordo com a Albras, segundo o qual a empresa deve priorizar o recrutamento da mão-de-obra da microrregião onde se encontra instalada a sua unidade industrial ${ }^{4}$, desempenhando assim uma função social.

A ausência de tradição na indústria do alumínio levou a Albras a investir consideráveis recursos em treinamento de pessoal, para inicialmente formar mão-de-obra especializada (nível médio) no ramo do alumínio, como técnicos em metalurgia, eletricidade etc. Os custos da formação dessa mão-de-obra foram previstos no orçamento do projeto Albras e levaram em conta os "custos locacionais", dadas as condições "hostis e extrativistas" da região em que foi instalada a empresa.

Além dos treinamentos, essa empresa criou estratégias para fixar ${ }_{5} \mathrm{e}$ adaptar a mão-de-obra, como salário mensal acima da média regional e

\footnotetext{
${ }^{4}$ A Albras fica situada no município de Barcarena, no Estado do Pará, a 38 km de Belém, capital do Estado.
} 
uma política de benefícios sociais, dentre os quais se destacam os serviços de saúde (assistência médica/hospitalar), previdência social (complementação da aposentadoria), ticket refeição, subsídios às mensalidades escolares para os empregados e seus dependentes, transporte. Além dessas vantagens sociais, acrescenta-se também o aspecto habitacional: a empresa construiu (em etapas) uma vila habitacional para os empregados, nas proximidades de sua instalação, a qual é denominada "vila dos Cabanos" e possui toda uma infra-estrutura de urbanização, transporte, saúde, educação, lazer (clubes) etc., inexistente na própria cidade de Barcarena.

Esse conjunto de benefícios sociais fazem parte da pauta de negociação que o Simetal mantém com a empresa desde 1990, por meio de acordos coletivos; a cada ano, o sindicato conseguia novas conquistas sociais e trabalhistas. A partir de 1997, a empresa começou a reduzir determinados serviços e restringiu o número de favorecidos pelos mencionados benefícios, como pais e agregrados dos trabalhadores. Apesar disso, esses benefícios são fundamentais para a reprodução social dos trabalhadores e seus familiares na medida em que contribuem para a satisfação de determinadas necessidades básicas e, dessa maneira, passam a ser significativos do ponto de vista econômico, social e ideológico, pois o padrão de vida desses trabalhadores tende a ser determinado pelo salário percebido na empresa e pela utilização desses benefícios.

Esse fato pode estar relacionado com a situação de desproteção social a que a maioria dos brasileiros está sujeita. Com efeito, os serviços básicos de sobrevivência (saúde, habitação, educação etc.) são garantidos pelos salários e, em geral, não têm sido assumidos pelo Estado.

Pelo exposto, observa-se que a organização de trabalho na Albras aproxima-se do fordismo, principalmente no que se refere à reprodução social do trabalhador e de sua família: benefícios sociais, divisão do trabalho por meio de sua estrutura hierárquica, trabalho especializado e parcializado, negociações coletivas entre o sindicato e a empresa. Essa forma de organização de trabalho transcende os muros do espaço fabril por meio da institucionalização de um conjunto de benefícios sociais salários indiretos - a fim de garantir determinado padrão de consumo dos empregados e de seus familiares e, em conseqüência, a sua reprodução social enquanto trabalhadores.

Com isso, pode-se dizer que a organização de trabalho da Albras influiu na organização política dos trabalhadores dessa empresa. De

\footnotetext{
${ }^{5}$ É importante explicitar que de 1.410 trabalhadores da Albras existentes até julho 1998, 1.127, situavam-se na faixa salarial correspondente entre $R \$ 509,00$ reais à $R \$ 1.549,00$ reais.
} 
fato, desde 1990, o Simetal tem defendido os interesses coletivos dos trabalhadores. Merece destaque, por exemplo, a memorável greve dos trabalhadores dessa empresa, ocorrida em 1991, quando o sindicato lutava por melhores condições de trabalho, aumento salarial etc. Outras conquistas sociais e trabalhistas têm sido atribuídas às lutas desse sindicato.

As considerações tecidas sobre um dos "enclaves fordistas" na Amazônia reforçam a idéia de que, realmente, o fordismo não se desenvolveu da mesma forma em todos os lugares. As variações foram bastantes significativas em função do grau de desenvolvimento econômico, do tipo de organização sindical e da cultura política nacional. Destaca-se o caso da Amazônia, onde métodos arcaicos convivem com modernas técnicas de produção.

Dessa maneira, mesmo com a dualidade centro x periferia, o fordismo conseguiu um rápido desenvolvimento em certo número de países, chegando mesmo a ser concebido como um modo de viver e de pensar.

Entretanto, a partir do final dos anos 60 e início dos anos 70, após os chamados "trinta anos de ouro", o fordismo começa a ruir, enfrentando uma crise. A "crise" do fordismo tem sido objeto de ampla discussão nas ciências sociais. É, portanto, fundamental compreender em que consiste a crise do fordismo. Deve-se procurar uma resposta para algumas questões. Quais as implicações dessa crise para aorganização de trabalho na Albras? O que tem mudado na organização de trabalho dessa empresa? Os processos de trabalho? A forma de gestão da mão-de-obra? Qual a repercussão de tais mudanças na organização política dos trabalhadores ? Quais os impasses e desafios enfrentados por essa nova organização de trabalho, dados os interesses coletivos dos trabalhadores?

As respostas a esses questionamentos devem levar a uma compreensão geral da crise do fordismo e das mudanças na organização de trabalho da Albras e suas implicações para a organização política dos trabalhadores dessa empresa, foco deste trabalho.

1.2 A crise do fordismo: implicações para a organização de trabalho da Albras

Na interpretação sociológica, segundo Braga (1995), a crise do fordismo tem sido explicada, principalmente, por duas teorias: a teoria da regulação e a da especialização flexível, que unificam a problemática pós-fordista e, grosso modo, afirmam que um maior crescimento só é 
possível no interior de uma determinada estrutura institucional reguladora, capaz de conciliar o crescimento econômico auto-sustentado com a harmonia e o progresso social. Contudo, em uma outra perspectiva sociológica, a causa da crise do fordismo é a crise contemporânea, como a crise orgânica do capital. Isso significa que a crise do fordismo constitui a mais evidente síntese das contradições e dos antogonismos amadurecidos no âmbito de uma particular correlação de forças estabelecidas entre a buguesia, as classes subalternizadas e os EstadosNações, ao longo do processo de expansão do imperialismo ocidental, em concorrência com o bloco coletivista do Estado - o chamado socialismo real - entre os anos 50 e 70 do século XX (BRAGA, 1996).

Sendo assim, a crise do fordismo, "inaugurada" em 1973 com a crise do petróleo, decorre, na verdade, de uma crise generalizada das exigências da acumulação do capital em âmbito internacional, ligada à crise de consentimento das classes subalternas ao projeto colonialista ou neocolonialista, no âmbito de cada formação nacional específica, incluindo-se aí a crise generalizada do welfare do Estado burguês, no caso dos países imperialistas.

A modificação das bases sobre as quais estava assentada a antiga lógica da correlação de forças entre dominantes e dominados, e a composição social das classes subalternas, conforme as modalidades desua intervenção política por meio de sindicatos industriais burocratizados e partidos de massa no projeto hegemônico socialdemocrata, levaram à crise do chamado Welfare State, pois, de uma relativa passividade, as massas de trabalhadores passaram à atividade, provocando, assim, a crise desse Estado e a dispersão das classes dominantes, traduzidas na falta de confiança nas instituições: família, imprensa, parlamento, exército, Igreja (BRAGA, 1996).

O capital, por intermédio das classes dominantes, reagiu a essa situação, sobretudo nos anos 70 e 80, com a elaboração de contratendências $^{6}$ para retardar as conseqüências das tendências à queda da taxa de lucros. Nesse processo, aquele período assistiu a uma profunda reestruturação produtiva, bem como a alterações sociais e políticas. Isso posto, o estabelecimento de um novo equilíbrio instável passa a exigir a reorganização do papel das forças produtivas na recomposição do ciclo de reprodução do capital, tanto na esfera da produção, como na esfera das relações sociais. Intensificam-se então os

${ }^{6}$ Essas contratendências assumidas pelas classes dominantes, objetivando a recomposição do capital, a partir dos anos 70 e 80, foram observadas sobretudo nos países de capitalismo avançado. No Brasil em particular, esse processo inicia-se nos anos 90, com o governo Collor. 
métodos de trabalho, modificam-se as formas de vida dos trabalhadores, estabelecem-se as novas bases políticas e sociais que permitirão às classes dominantes apresentar seus interesses particulares como universais, isto é, válidos para todos.

As empresas em geral, a partir dos anos 70, 80 e 90, para recompor seu capital, passaram a adotar novas estratégias que expressam a capacidade política e cultural da burguesia de absorver a bandeira de lutas dos trabalhadores, de forma que eles assimilem elementos importantes de seus programas por intermédio de seus intelectuais, o que tem fragilizado a organização política dos trabalhadores, alterando, assim, a relação de forças na relação capital x trabalho.

Dentre as estratégias de recomposição do ciclo de capital, destaca-se a tendência a promover uma revolução técnica. Assim, o desenvolvimento das forças produtivas por meio da automação, da robótica e da microinformática faz com que o padrão fordista de produção fabril e a organização de trabalho taylorista deixem de ser os únicos modelos dominantes nos processos de trabalho. Isso tem levado ao surgimento de um conjunto expressivo de processos produtivos no interior do capitalismo que de alguma forma alteram ou substituem o padrão fundado no binônimo taylorismo-fordismo.

Foi assim que surgiu o Ohnismo, uma nova forma de organização de trabalho que de certa forma rompe com o trabalho parcelado na montagem, típico do fordismo, na medida em que propõe o trabalho em equipe, fundamentado no envolvimento da força de trabalho no universo e no ideário da empresa. Essa forma de organização de trabalho vai de encontro ao controle rígido de tempos e movimentos, ao controle da produção pelos escalões hierárquicos da fábrica, por intermédio dos mestres e contramestres. O trabalhador passa a ser o seu próprio "vigia", tornando-se, no dizer de Antunes (1996), 'déspota de si próprio", visto que ele não mais se avilta pelo "chicote", mas se avilta no plano do idéario; a empresa passa a ser vista como "a sua empresa; a produtividade é a produtividade da empresa" (ANTUNES,1996).

Castro (1995b) faz uma análise detalhada dessa nova forma de organização de trabalho. Segundo a autora, essa organização de trabalho descaracteriza uma concepção-chave do fordismo, que é o posto de trabalho, base da cronometragem do tempo e da produtividade. Admite-se aí a polivalência das funções com a finalidade de reduzir os custos e aumentar a produtividade. Reduzindo-se os postos de trabalho na empresa, aumentam as tarefas que o trabalhador deve executar.

A alteração na organização de trabalho em bases tayloristas/for- 
distas provoca também a alteração na organização política dos trabalhadores, sobretudo nos sindicatos operários, os quais, desde o fim da Segunda Guerra Mundial, constituem uma força expressiva na relação capital x trabalho. De fato, à medida que a empresa difunde o seu ideário de que "a empresa é o trabalhador" e "o trabalhador é a empresa", obscurecem-se as relações de classe, o que contribui para o esvaziamento da luta dos sindicatos. Ocorre então o que Gramsci chamou de revolução passiva, visto que o objetivo de tal ideário é fomentar a recomposição de todo um campo ideológico. De fato, com a atual estratégia de passivização dos trabalhadores, o neoliberalismo tenta suprimir as forças antagonistas.

Isso é visivelmente percebido na passivização das conquistas históricas das classes subalternas expressas nas lutas sindicais, que a cada dia têm se intensificado por meio da nova ordem hegemônica, enquanto produto dessa revolução passiva, pois os interesses do capital e do trabalho continuam sendo concretamente coordenados, porém onde o trabalho costumava receber alguns ganhos com base na expressão dos lucros, ele agora faz concessões com base na lucratividade relativa dos capitalistas.

Com efeito, em virtude da subalternidade política dos trabalhadores, o movimento dos trabalhadores organizados não consegue enfrentar os desafios impostos pelas estratégias adotadas pela força hegemônica do capital industrial (anos 70). O resultado é uma revolução passiva das referidas organizações políticas, neste período de "crise de lucratividade". Assim, os trabalhadores estão em um impasse: têm de optar entre os cortes de salários e das conquistas sociais, a sujeição à intensificação do trabalho polivalente e a perda do emprego. Tal impasse pode ser notado nas negociações coletivas, em que geralmente as empresas buscam flexibilizar o uso do trabalho por meio da determinação da classificação das ocupações, da adoção de formas de gestão e de uso do tempo de trabalho mais flexíveis e modulares, de mudanças das regras e normas para a determinação dos salários, com uma crescente individualização do processo.

A individualização dos salários contribui para a passivização dos trabalhadores porque enfraquece sua organização política e divide ainda mais os trabalhadores. O trabalho em grupo adapta-se preponderantemente à produtividade, mas não se adapta à distribuição do lucro (salário), que se dá de forma individualizada. Constata-se que as negociações coletivas, instituídas sobretudo após a Segunda Guerra Mundial, eram amparadas pelos sistemas públicos de regulação das relações de trabalho e defendiam uma classificação de ocupações, o que, 
de certa forma, dava uma relativa "estabilização" às relações de trabalho. Hoje, por causa da instabilidade dos salários, não podem mais ser sustentadas.

Sendo assim, as políticas salariais devem ser novamente discutidas dentro das empresas, abandonando-se as políticas negociadas ou as regulações públicas, rompendo-se, assim, gradativamente, com a tradição da negociação "empresa x sindicato x Estado". Isso implica a alteração do papel do Estado no que se refere à regulamentação do mercado de trabalho e a redução de seu poder de manter, alterar ou criar as regras e normas do mundo do trabalho. Só assim seriam possíveis as negociações diretas. As empresas devem ter autonomia para contratar sua força de trabalho, conforme as flutuações no nível e na composição de sua demanda (DEDECA, 1996).

Nesse sentido, as empresas, por via de regulação estatal, instituem os contratos por tempo indeterminado ou parcial que, em geral, são adotados para os trabalhadores menos qualificados. Para os mais qualificados, as empresas tendem a lançar mão de outros mecanismos de flexibilização das relações de trabalho, como, por exemplo, incentivos para que parte desses trabalhadores se demita e forme microempresas para prestar serviços ao seu antigo empregador. Outros trabalhadores submetem-se a certas alterações no uso e na remuneração da força de trabalho, particularmente no que tange à gestão do tempo (horário) de trabalho.

A nova forma de organização do trabalho altera o processo de determinação do salário, as funções e o uso do trabalho, modificando as regras anteriores de formação dos salários, atingindo os trabalhadores que pertencem ao segmento interno e mais estável da estrutura ocupacional da empresa. As empresas tendem a vincular a remuneração dos trabalhadores mais estáveis à "performance individual"; já os trabalhadores com pouca estabilidade são remunerados por meio de contrato por tempo indeterminado. Os salários levam em conta múltiplos aspectos da performance do trabalhador, como produtividade individual, resultado obtido pela empresa, nível de absenteísmo individual, criatividade no enfrentamento dos problemas cotidianos do processo produtivo, rendimento de equipe de trabalho etc.

Se, por um lado, a flexibilização das relações de trabalho constitui uma das estratégias adotadas pelas empresas para enfrentarem os riscos inerentes aos investimentos ligados à modernização tecnológica e à organização da produção, por outro, expressa a desarticulação do sistema de normas estabelecidas. Isso implica a elaboração de uma outra forma de regulação que estabeleça critérios mais adequados à recomposição 
do capital. No caso brasileiro, tal regulação tem sido feita pelo governo que, em nome da eficiência e da equidade do mercado, propõe-se a criar condições objetivas para a modernização das relações de trabalho. Com isso, o Estado deixa de assumir o controle das normas, leis e procedimentos trabalhistas e propõe o "entendimento entre as partes", ou seja, a negociação entre trabalhadores x empresários. Dessa forma, tanto os trabalhadores, quanto os empresários passariam a ter autonomia na definição dos reajustes salariais, mediante a negociação coletiva. Na área do trabalho, o Estado ficaria responsável pela implementação de políticas de qualificação profissional e de fomento do emprego.

A despeito dessa modernização nas relações de trabalho, cuja palavra de ordem é o diálogo, que pressupõe a negociação, é preciso verificar se os trabalhadores podem negociar, se a hegemonia do grande capital industrial, materializada em estratégias políticas, ideológicas e econômicas, tem enfraquecido a organização política dos trabalhadores. Como negociar, se na atual crise de lucratividade, os operários têm de optar, ou por cortes de salários e pela extinção de conquistas sociais, ou pela perda do emprego? Há realmente uma proposta de negociação ou se trata de mais uma nova tentativa de recomposição do capital, que, disfarçada no discurso de modernização, tem possibilitado a passivização com o "consentimento" dos trabalhadores?

Na realidade, a modernização das relações trabalhistas "obscurece" uma nova forma de hegemonia do grande capital, uma vez que altera as formas caracterizadas pelos mecanismos legais, mas não altera o conteúdo, que é a lógica do mercado. A flexibilização dos contratos de trabalho, por exemplo, que, essencialmente, reduz os custos, proporciona a extração da mais-valia, aumentando a taxa de lucros e atacando os direitos conquistados pela classe trabalhadora. É a "modernização sem modernidade" que, seguindo a lógica neoliberal, enfraquece a luta de classes, construindo uma política que parece afastar-se, de forma acelerada e vertiginosa, da justiça social e da busca da igualdade e da fraternidade enre as pessoas e os povos. Desse modo, essas alterações são não somente de caráter quantitativo, como, por exemplo, a diminuição do volume de empregos, mas também de natureza qualitativa: de fato, constata-se a evolução de formas de precarização do trabalho e de deslegitimação das antigas contratualidades; além disso, aumentam as incertezas e os riscos do mercado, não apenas no setor privado, mas também nas organizações públicas (CASTRO, 1995a).

No Brasil, esse quadro tem sido marcado pela introdução de novos métodos de produção, com pouco uso de mão-de-obra, o que requer uma qualificação profissional cada vez maior, dada a exigência 
de qualidade na produção imposta pela competividade internacional. As empresas têm informatizado setores, o que permite a difusão de informações dentro da empresa de forma mais rápida, aumentando a rentabilidade do trabalho e acelerando a resolução dos problemas que surgem na produção. Na gestão pela qualidade total, destaca-se a técnica conhecida como $5 \mathrm{~S}$ (cinco sensos) : SEIRI (organização), SEITON (arrumação), SEISON (limpeza/zelo), SEIKEITON (higiene) e SHITSUKE (auto-disciplina). Essa técnica institui um certo padrão de comportamento, forjando uma cultura do trabalho baseada nos interesses da empresa, o que fragiliza a força política dos trabalhadores em geral.

Essa cultura do trabalho tem invadido os modos de vida do trabalhador. Extrapolando, inclusive, o âmbito da fábrica, impõe uma nova relação de trabalho e, portanto, novas relações de força, marcadas por um "consenso" que implica a passivização do trabalhador.

Tecidas essas considerações, cabe perguntar: quais são as particularidaes dessas estratégias na Albras e de que maneira elas interferem no Simetal? Quais são os impasses e desafios impostos a essa organização política a partir da adoção dessas novas estratégias na referida empresa?

\subsubsection{Nova organização de trabalho na Albras}

A Albras, para fazer face às novas exigências de competividade internacional, visto que a sua produção está voltada quase exclusivamente para o mercado internacional, não poderia ficar inerte diante dessa realidade. Assim, desde o início dos anos 90 e com maior intensidade nos últimos anos, assimilando a lógica mundial, tem introduzido novas tecnologias nos processos produtivos - automatização, microeletrônica, informatização - e nas relações de trabalho - Kanban, polivalência, terceirização, Gestão pela Qualidade Total (GQT) .

A adoção de tais tecnologias têm contribuído para a reconstrução da hegemonia da empresa graças à adesão de seus trabalhadores, expressa no abandono da luta por seus interesses, dada a alteração nas forças políticas estabelecidas na referida empresa. Isso certamente fragiliza a principal organização política dos trabalhadores - o Simetal. A hegemonia da empresa tem sido fortalecida não só pela introdução dessas novas tecnologias, mas também pela adoção de sutis mecanismos de "sedução" que levam os trabalhadores a se afastar cada vez mais do

\footnotetext{
${ }^{7}$ Em fevereiro de 1999, a empresa possuía 533 empregados contratados por empresas prestadoras de serviços e 1.410 trabalhadores em seu quadro de pessoal.

${ }^{8}$ A propósito da GQT na Albras, ver sobretudo Castro (1995b, 1998) e Carmo (1997).
} 
enfrentamento do antagonismo capital x trabalho.

Como exemplo, destaca-se o fato de a empresa tentar persuadir seus trabalhadores a envolver-se nos negócios da Albras, com base na idéia de que "o trabalhador é a empresa, e a empresa é o trabalhador".Tal ideário tem sido muito difundido na empresa, quer seja em reuniões entre chefias e trabalhadores, quer seja em cursos e seminários, boletins internos da fábrica (bif) etc., e está assentado no pressuposto de que, se a empresa vai bem, o trabalhador também terá possibilidades de "garantir" a sua reprodução social e a de sua família. Ora, isso não representa a realidade para a totalidade dos trabalhadores, visto que as estratégias de inserção no mercado internacional utilizadas pela Albras, em geral, são poupadoras de mão-de-obra, o que engraquece a força política do Simetal.

No que tange aos processos produtivos, uma das principais modificações observadas refere-se aos fornos: antes eram semiautomáticos, abertos; hoje funcionam por meio da compensação magnética com base em um sistema central de computadores, os quais efetuam o controle geral de toda a fábrica, aliado ao controle de qualidade do produto - lingote do alumínio - por meio da GQT.

Em relação à gestão de trabalho, a empresa tem estimulado mudanças por meio da GQT, da polivalência, da terceirização e das técnicas de Kanban e 5 S.

Para a empresa, a introdução dessas tecnologias têm possibilitado significativos ganhos de produtividade graças ao melhor aproveitamento da matéria-prima (redução de desperdícios), ao aumento da produção com qualidade, à redução do custo de mão-de-obra etc. À medida que substitui o trabalho vivo pelo trabalho morto e subcontrata mãode-obra (terceirização), a empresa reduz gastos com benefícios sociais e melhora a otimização do tempo necessário para o trabalho. Para os trabalhadores, essas mudanças tecnológicas têm alterado os processos de trabalho, com repercussão na subjetividade, na forma de reprodução social enquanto trabalhadores assalariados, o que também influi na reprodução social de sua família e fragiliza o Simetal, enquanto organização política desses trabalhadores.

No que tange à subjetividade do trabalhador, as conseqüências dessas mudanças podem ser notadas nos seguintes aspectos: imposição do trabalho polivalente, o que requer constante qualificação e requalificação do trabalhador em todos os níveis hierárquicos, mudança comportamental , por ser exigido um novo perfil dos empregados: próatividade, iniciativa, busca de auto-desenvolvimento, melhoramento na comunicação nas relações interpessoais, habilidade no trabalho em grupo 
etc.

As exigências comportamentais do novo perfil de trabalhador evidenciam a importância do trabalho vivo para o aumento da produtividade, embora, contraditoriamente, a empresa incentive cada vez mais o trabalho morto, ou seja, o uso de tecnologias que diminuem gradativamente o número de trabalhadores. Tal fato confirma a conhecida tese de Marx, segundo a qual a força de trabalho é a fonte de mais-valia e o capital é uma certa quantia de trabalho armazenado e acumulado. Assim, nos últimos anos, a Albras instituiu uma política de gestão de pessoas denominada Política do Ser Humano, que compreende seleção de pessoal, educação no trabalho, remuneração/carreira, qualidade de vida, relação com o empregado e com a vizinhança. Essa política não poderia ter outro objetivo senão a "adequação" dos trabalhadores ao aumento da produtividade e, ao mesmo tempo, a criação de mecanismos de coerção. Destaca-se, como exemplo, o fato de que a empresa tem modificado significativamente o seu plano de cargos e salários por meio da redução do número de cargos e do aumento das funções, dada a instituição do trabalho polivalente, o que resulta na maior extração da maisvalia. Além disso, a redução do número de cargos implica a diminuição dos níveis hierárquicos, o que torna a comunicação mais ágil, na medida em que propicia uma maior proximidade entre os gerentes e a equipe de trabalho. Assim, determinadas reivindicações, que antes eram levadas pelos trabalhadores ao Simetal, atualmente são "absorvidas " pelos gerentes. Diante disso, observa-se um maior controle político dos trabalhadores e, em conseqüência, o "esvaziamento" do Simetal. Para cumprir as novas exigências de gestão de pessoal, os gerentes devem possuir habilidades não só na gestão dos processos produtivos, mas também na gestão de pessoas.

As modificações nos processos produtivos propiciaram significativas melhoras nas condições de trabalho da Albras, no que se refere tanto aos aspectos físicos/ambientais, quanto ao clima organizacional estabelecido por meio das relações de trabalho.

Quanto às condições físicas de trabalho, a mudança tecnológica dos fornos por meio da compensação magnética contribuiu para evitar que os trabalhadores fiquem totalmente expostos ao calor (temperatura

\footnotetext{
${ }^{9}$ A Albras possui um código de ética, que norteia o comportamento dos empregados na difícil relação entre os empregados, a empresa e o poder público externo. Esse código de ética expressa o pensamento corporativo e institucional da Albras, situando a empresa no nível mais avançado entre as empresas que trabalham com qualidade total (Maurício Schettino, presidente da Albras).
} 
de $\left.41,6^{\circ} \mathrm{C}\right)$. Nas relações de trabalho, os trabalhadores tornaram-se mais "polidos" no trato com os colegas e assumiram a responsabilidade pelo estabecimento de um clima psicológico favorável à produtividade.

Ao mesmo tempo que essas melhorias aumentam a eficiência da produção, parecem também "cimentar" a passivização dos trabalhadores: como as melhorias traduziriam uma "preocupação" da empresa com o seu capital humano, são aceitas por todos os trabalhadores. Antes (pelo menos há cinco anos), não raro, trabalhadores desmaiavam durante o trabalho, em decorrência do excesso de calor no ambiente da fábrica. Mas é preciso salientar que, mesmo com essas melhorias, o trabalho na empresa (área de produção) continua sendo agressivo, pois não diminuíram os riscos sociais inerentes ao trabalho de beneficiamento de alumínio, em que pese todo o investimento na política de segurança, na qual a prevenção de acidentes e de doenças ocupacionais adquiriram maior relevância. Com as novas medidas, a Albras recebeu a segunda premiação da Associação Brasileira de Prevenção de Acidentes, por apresentar a menor taxa de acidentes de trabalho no ramo do alumínio.

Se, por um lado, a melhoria nos processos produtivos favorece melhorias nas condições objetivas de trabalho, por outro, afeta também a subjetividade dos trabalhadores: por não estarem acostumados com a nova rotina de trabalho, têm de se desdobrar para cumprir as inúmeras tarefas polivalentes, isto é, passam a desempenhar ações que se estendem desde o planejamento até a execução do processo produtivo. Os trabalhadores devem ainda apresentar soluções para os problemas que surgem por ocasião da realização do trabalho.

Forçados a participar do projeto hegemônico da empresa, os trabalhadores são obrigados a ampliar seus conhecimentos. Não basta ter o segundo grau completo (nível mínimo de escolaridade exigido); é necessário, por exemplo, aprender inglês e ter noções de informática.

Esses requisitos aplicam-se a todos os empregados da empresa. Se essas exigências não estivessem associadas à ameaça da perda de emprego, seriam extremamente favoráveis ao crescimento pessoal e profissional dos trabalhadores, visto que os estimula a aumentar seus conhecimentos e a explorar seu potencial criativo. Na realidade, atender a tais exigênciasprofissionais representa a possibilidade de manutenção do emprego. O que se questiona, além da emancipação dos trabalhadores, é a reprodução social dos trabalhadores. É certo que a empresa oferece determinados benefícios sociais importantes para a sobrevivência dos trabalhadores e de seus familiares, mas há também a 
falta de opção de emprego. Com efeito, a empresa encontra "campo fértil" para o fortalecimento de seu projeto hegemônico, pois é incontestável que esse "mínimo" obtido por meio da venda da força de trabalho nessa empresa pode significar o "máximo" que a maioria dos trabalhadores nunca teve. Em virtude das forças coercitivas da empresa, os trabalhadores percorrem o caminho que vai do "envolvimento" à adesão" ao projeto da empresa e, em conseqüência, ao enfraquecimento de sua organização política.

Não se pode deixar de mencionar também que o fortalecimento do projeto da empresa deve-se em grande parte à adoção da GQT, que vai muito além de uma forma de gestão, parecendo mesmo constituir uma ideologia, na medida em que os trabalhadores têm aderido aos princípios da qualidade como um modo de vida, tanto no interior da fábrica, quanto nas suas residências. A propósito, a qualidade torna-se um conceito-chave na Albras, e a GQT é empregada em todos os processos de trabalho: administrativo (financeiro, jurídico e social) e operacional (produção). A GQT abrange técnicas trazidas do modelo japonês de gestão, como Kanban, 5 S, just-in-time, o trabalho em equipe e o acompanhamento de gráficos e processos.

Pode-se dizer que a ideologia da qualidade total representa uma nova direção cultural para os trabalhadores da Albras, pois a qualidade tem se tornado o grande "alvo" a ser atingido por esses trabalhadores: qualidade na produção, qualidade nas relações de trabalho, qualidade na vida profissional, pessoal e familiar. No âmbito da produção, foram instituídos os Círculos de Controle da Qualidade (CCQ), assentados nos princípios da participação de todos e do trabalho em equipe: todos são responsáveis pela satisfação do "cliente", tanto o interno (empresa), quanto o externo (mercado).

A satisfação do cliente está ligada à satisfação dos próprios trabalhadores no que tange ao trabalho que realizam: devem sentir orgulho do seu trabalho e da empresa, devem empolgar-se! Há, evidentemente, um "apelo" ao aspecto emocional dos trabalhadores; pode-se mesmo falar em "psicologização do político", porque a empresa adota formas de persuadir os trabalhadores de sua satisfação, a despeito, por exemplo, dos riscos ambientais, da redução de benefícios sociais, das profundas inquietações e preocupações com o salário, com o volume de trabalho e até com a iminente perda do emprego, em nome da empregabilidade.

No plano pessoal, a idéia da qualidade está relacionada com o aspecto comportamental: o trabalhador é "chamado" a administrar os seus conflitos pessoais; deve ter habilidades para se relacionar e se 
comunicar com todos os segmentos da empresa, de forma a zelar pelo clima organizacional favorável à produtividae. Em "nome" da melhoria contínua - leia-se "qualidade" -, é exigido do trabalhador um comportamento "pró-ativo" que o leve a pensar nos problemas antes que aconteçam, que o torne solidário com os colegas diante das dificuldades ocorridas no trabalho. Não são mais permitidas na empresa atitudes egoístas do tipo "eu sei, tu não sabes"; assim, é exigida de cada trabalhador solidariedade na equipe de trabalho, porque a "empresa é o trabalhador e o trabalhador é a empresa".

A qualidade total chega à casa dos trabalhadores, principalmente por meio dos $5 \mathrm{~S}$. As informações sobre esses "sensos" são veiculadas pelos próprios trabalhadores ou por ocasião das visitas oficiais de familiares na Albras, no âmbito de um programa corporativo denominado "Integração Família x Empresa". Aliás, esse programa tem constituído também um dos mecanismos de difusão do projeto hegemônico da empresa, pois favorece uma maior aproximação das esposas dos trabalhadores que, dessa maneira, passam a compreender melhor o desgaste físico ao qual seus maridos estão expostos, os seus horários de trabalho, muitas vezes responsáveis pelas ausências da família.

A empresa faz uma intensa difusão do ideário da qualidade em todos os segmentos que podem atingir o trabalhador, pois, dada a acirrada competitividade internacional, precisa persuadir os trabalhadores de seus compromissos com a qualidade e a produtividade. É meta da empresa atingir os melhores padrões de desempenho, para manter-se entre as cinco melhores empresas do mundo no ramo do alumínio. Esse ideário invade "corações e mentes" e, conseqüentemente, faz surgir uma nova cultura, que, ao consolidar a hegemonia da empresa, parece dissolver a identidade de classe, fragilizando a organização política dos trabalhadores.

\section{2 - NOVA ORGANIZAÇÃO DE TRABALHO NA ALBRAS: IMPLICAÇÃO PARA A ORGANIZAÇÃO POLÍTICA DOS TRABALHADORES}

É incontestável que a nova organização de trabalho na Albras tem influído na organização política de seus trabalhadores, visto que as

\footnotetext{
${ }^{10}$ A empregabilidade é entendida como um conjunto de atributos pessoais e profissionais ligados a conhecimentos técnicos ambientais, e ainda ao padrão de relacionamento pessoal e atitude frente a tarefa, sintonizada com as necessidades do mercado de trabalho que determina hipotéticamente as chances dos indivíduos profisionalmente.
} 
estratégias utilizadas pela empresa contribuem para o fortalecimento do seu projeto de acumulação do capital. Ao "aderir" a tal projeto, os trabalhadores assumem outro projeto de classe social, que não é o da classe à qual pertencem, o que, além de dificultar significativamente a criação de um contramovimento que leve ao fortalecimento político dos trabalhadores, tem fragilizado o Simetal. Esse fato tem sido observado também em outros sindicatos brasileiros (conforme já referido neste trabalho) e tem gerado inúmeras polêmicas nessas organizações de trabalhadores, levando-as a uma crise profunda. Constata-se o esvaziamento da mobilização para a luta em defesa dos interesses dos trtabalhadores. Diante do cenário geral do sindicato brasileiro e da nova organização de trabalho da Albras, cabe perguntar quais são as implicações políticas dessa organização para o Simetal. E mais: quais são os principais impasses e desafios que ele enfrenta atualmente para criar um movimento contrário ao projeto da Albras, que defenda os interesses coletivos dos seus trabalhadores e da sociedade em geral?

Antes de tentar responder a essas questões, é importante lembrar que, dos aproximadamemte 7.000 trabalhadores desse ramo de atividades, 2.600 eram filiados ao Simetal, dos quais 450 eram trabalhadores da Albras, o que correspondia a 30\% do total de trabalhadores (1.410) dessa empresa na época da realização da pesquisa que subsidiou esta reflexão. Importa registrar também que o Simetal, desde o seu surgimento em 1931, tem lutado em defesa dos interesses da categoria dos trabalhadores da indústria metalúrgica, por meio da negociação de acordos coletivos, conforme as relações de forças de cada empresa desse ramo de atividade industrial.

No que tange ao caso específico da Albras, essa organização política tem efetuado inúmeros acordos coletivos. Sua pauta de negociações tem sido definida em assembléias específicas para esse fim. Com efeito, o sindicato obteve significativos ganhos não só na conquista de benefícios sociais, mas também na articulação de forças políticas dentro da Albras ${ }^{11}$. Contudo, nos últimos anos, o Simetal tem encontrado sérias dificuldades para negociar certas propostas, em razão da hegemonia da referida empresa sobre os trabalhadores. Assim,

\footnotetext{
${ }^{11}$ Registra-se que o Simetal trabalha em sintonia com duas comissões dentro da fábrica: a Comissão Interna de Meio ambiente (CIMA) e a Comissão Bilateral. Esta última tem como atribuição discutir, formular propostas e recomendações com relação a cursos de aperfeiçoamento profissional, acompanhar a aplicação da legislação trabalhista, zelar pelos programas de benefícios sociais. Segundo alguns dirigentes do Simetal, ela tem sido um espaço político de articulação de forças dentro da fábrica, embora, atualmente, nem sempre as propostas apresentadas por essa comissão sejam atendidas pela empresa, que impõe os seus interesses, dominando assim os trabalhadores.
} 
as lutas dessa organização de trabalhadores têm se concentrado na garantia do emprego para os trabalhadores, na manutenção dos benefícios sociais e na participação nos resultados da empresa.

Quanto à garantia do emprego, o Simetal tem direcionado a sua luta para a qualificação e a requalificação dos trabalhadores, mais especificamente para os novos requisitos profissionais: nível escolar de 2. 'grau, conhecimentos sobre informática e sobre uma língua estrangeira. Se os trabalhadores não preencherem tais requisitos, correm o risco de ser demitidos por não possuírem a competência necessária para operar com qualidade os novos equipamentos. Ao defender a qualificação de seus associados, o próprio Simetal está contribuindo para a difusão do projeto da empresa entre os trabalhadores, na medida em que legitima a "seleção natural" dos mais qualificados para corresponder ao novo perfil de trabalhador da Albras. Não se está menosprezando a iniciativa do Simetal de buscar maior qualificação profissional, principalmente para aqueles trabalhadores que ainda não possuem tal qualificação e não dispõem de recursos para custeá-la ${ }^{12}$. Entretanto, o que merece ser questionado é: até que ponto o Simetal, com essas medidas, não contribui ainda mais para a hegemonia da empresa? Afinal, o que é modernização para os dirigentes sindicais? Apenas a inovação tecnológica?

Não se pode negar a importância do avanço tecnológico na Albras, que tem possibilitado melhorias nas condições de trabalho e atenuado os riscos profissionais. Contudo, chama a atenção o fato de a direção sindical parecer ignorar o volume de trabalho a que os empregados estão sendo submetidos em decorrência da polivalência e a tensão emocional desencadeada pelo risco iminente de demissão em função das inovações tecnológicas e da estratégia de redução de custos que tem sido adotada pela empresa.

Embora o Simetal tenha tentado negociar para treinar novamente os trabalhadores que poderão ser demitidos por não se enquadrarem no novo perfil de profissional exigido pela empresa - o que lhes permitirá ser alocados nas novas reduções que serão implantadas na empresa -, o que mais "salta aos olhos" é o fato de o Simetal parecer incorporar o projeto da empresa e tentar "adequar" os trabalhadores a esse projeto, ao invés de apresentar uma proposta política contra a hegemonia da empresa, limitando-se a reagir às exigências da Albras para que os trabalhadores se tornem mais produtivos. Alguns dirigentes sindicais

\footnotetext{
${ }^{12}$ Segundo a gestão de pessoas da Albras, existem ainda 560 trabalhadores que não possuem o 2. ${ }^{\circ}$ grau completo: 12 concluíram apenas o primário, 435 cursaram o 1. ${ }^{\circ}$ grau (alguns não o concluíram) e 113 não terminaram o $2 .^{\circ}$ grau.
} 
afirmaram que o Simetal, a partir de 1995, passou a ser mais propositivo. Segundo eles, um exemplo disso são as ações desenvolvidas no âmbito do Programa Integrar. Para eles, esse programa não tem como objetivo apenas garantir a manutenção nos postos de trabalho por meio da qualificação/requalificação, mas se propõe também a formar cidadãos. Nota-se, porém, que esses dirigentes sindicais tendem a considerar o referido programa como um meio para atender às exigências de qualificação para o mercado e não para permitir a emancipação do trabalhador enquanto pessoa e cidadão. Sendo assim, pergunta-se: até que ponto o Programa Integrar tem alterado as relações de força existentes atualmente na Albras? Tal questão parece ganhar maior importância quando se considera a quantidade de beneficiários do mencionado programa. Segundo a sua coordenadora no Estado do Pará, por causa dos recursos limitados de que dispunha em 1999, o programa atingia 180 alunos. É verdade que a iniciativa do Simetal faz parte de uma proposta nacional da maior organização política dos trabalhadores (CUT) e que suas ações (qualificação profissional/requalificação) respondem a certas necessidades dos trabalhadores do ramo da metalurgia e dos trabalhadores em geral. Entretanto, tal estratégia é insuficiente para lutar contra o projeto hegemônico da Albras, que por sua vez está ligado à hegemonia do grande capital internacional, o que pressupõe a elaboração de estratégias mais ambiciosas e mais gerais, que não se limitem às ações pontuais da Albras. Assim, a estratégia de formação profissional que o Simetal tem utilizado para garantir o emprego dos trabalhadores na Albras precisa ser questionada. Não se pode deixar de lembrar que existem projetos de ampliação da automação e de implantação de outras inovações tecnológicas para fazer face ao mercado competitivo internacional que são poupadoras de mão-de-obra.

Diante desse quadro, o Simetal parece estar em um grande impasse. De fato, como organização política dos trabalhadores, deveria contribuir para a construção de um projeto que privilegie a identidade de classe do ponto de vista do trabalhador, o que certamente extrapola as lutas preponderantemente voltadas para as questões econônomicas, envolvendo negociações salariais, benefícios sociais, participação nos resultados da empresa. Dessa forma, os trabalhadores estariam ligados por um pensamento único classista. Além disso, os interesses de classe ficariam consolidados, e não fragmentados por causa da adesão ao projeto hegemônico da empresa. Isso decerto requer o amadurecimento dos próprios trabalhadores no que tange à democracia, o que pressupõe habilidades na convivência com as diferenças partidárias. Sabe-se que as divergências partidárias entre os sindicalistas, principalmente entre 
os dirigentes, têm provocado o esvaziamento sindical. Efetivamente, em certas reuniões dessa organização de trabalhadores, uma significativa parte do tempo é ocupada com "ataques pessoais", que se desviam do interesse coletivo dos trabalhadores.

Fatos dessa natureza, sem dúvida, favorecem ainda mais o fortalecimento da hegemonia da empresa sobre os trabalhadores. Grande é o poder de "sedução" da empresa para a adesão a seu projeto - um exemplo disso é a utilização da GQT que, em nome da valorização do capital humano, institui prêmios por produtividade, cria mecanismos para um relacionamento mais "polido" entre os vários segmentos da hierarquia da empresa, o que tem levado determinados trabalhadores a "substituir" o sindicato pelos gerentes da empresa na resolução de certas questões trabalhistas.

A busca de "saídas" individuais para os problemas dos trabalhadores resulta na diminuição de sua participação nas atividades do Simetal. Pergunta-se: por que esses trabalhadores não participam de sua organização política com o mesmo entusiasmo que demonstram em sua participação nas atividades dos CCQs? Esse fato estaria relacionado ao "medo" da perda do emprego? E mais: por que temer o exercício de um direito de todo cidadão brasileiro , que é a participação? Por que os trabalhadores exercem esse direito de forma mais efetiva, quando se trata dos interesses da empresa?

As "saídas" individuais podem ser apenas imediatas, mas decerto não constituem alternativas consistentes para o desafio de garantir o interesse da maioria dos trabalhadores da Albras e dos trabalhadores em geral, neste momento histórico. A construção de valores como o acesso ao trabalho, a conquista da autonomia, da liberdade e da realização pessoal, o que se traduz em emancipação social, depende do coletivo dos trabalhadores, enquanto sujeitos históricos, e da ruptura da dominação exercida pela Albras e pelo grande capital internacional.

Eis aí o grande desafio imposto ao Simetal e às demais organizações políticas dos trabalhadores, ligadas a outros movimentos sociais em âmbito internacional. É preciso, pois, extrapolar a organização corporativista baseada no sindicalismo industrial, cuja trajetória histórica parece ter estado sempre a "reboque" da organização de trabalho (taylorista, fordista, acumulação flexível) imposta pelas empresas. Somente assim é possível opor-se à hegemonia não só da Albras, mas também do grande capital internacional, de forma a garantir trabalho para todos, principalmente para aqueles que são mais precisam ter suas necessidades básicas atendidas. 
Finalmente, como Antunes (1999, p. 11), entende-se que toda a "classe-que-vive-do-trabalho" enfrenta o desafio de resgatar o sentido de pertencimento da classe trabalhadora. Essa classe tem um papel central na criação de riquezas para além do capitalismo, pois "mesmo mais fragmentada, heterogênea e complexificada, esta é a classe que vive do trabalho, que tem a possibilidade de virar a página da história" (ANTUNES, 1999).

\section{CONCLUSÃO}

As considerações tecidas sobre a organização política dos trabalhadores nos países centrais, na América Latina (sobretudo no Brasil), e em particular sobre o Simetal, indicam que, com o aparecimento do capitalismo industrial, foram lançadas as bases da formação dos trabalhadores assalariados. Em virtude da extrema extração da maisvalia pelos capitalistas, esses trabalhadores eregiram fortes movimentos políticos que chegaram mesmo a extrapolar as lutas corporativas, na medida em que incorporaram as lutas da sociedade em geral.

Nota-se que, geralmente, a organização política dos referidos trabalhadores tem representado uma resposta ao antagonismo de classes expresso nos "modelos" de organização de trabalho criados pelo capitalismo industrial em função de sua hegemonia. Em outras palavras, as organizações políticas dos trabalhadores iniciadas nos séculos XVIII e XIX e consolidadas no século XX, cuja maior expressão foi o sindicato, parecem ter acompanhado a direção política do capitalismo industrial. Assim, suas ações têm sido muito mais "defensivas" em relação às "ofensivas" do capital industrial, do que um projeto "da" e "para" a classe trabalhadora. Tanto que a nova divisão internacional do trabalho, chamada por alguns estudiosos de "pós-fordista" ou "acumulação flexível", tem provocado cada vez mais a fragmentação dos trabalhadores e, em conseqüência, a fragilização dos sindicatos. Como maior expressão da organização política dos trabalhadores, os sindicatos parecem ficar "atônitos", o que dificulta a criação de novas estratégias para lutar contra a hegemonia do capitalismo internacional. O Simetal parece ser um exemplo significativo dessa situação.

Pode-se então supor que existe a necessidade de uma revitalização da identidade de classe, que decerto extrapola a organização política dos trabalhadores criada no capitalismo industrial, para que sejam construídas novas referências e oportunidades de trabalho, para além 
do emprego. Desse modo, entende-se que o Simetal e as demais organizações de trabalhadores brasileiros enfrentam os seguintes desafios:

a) romper com a cultura corporativista, burocratizada e com as práticas de resultados imediatos e formular estratégias políticas e ideológicas para o enfrentamento da dominação exercida pela Albras e pelo capitalismo internacional;

b) articular uma rede de movimentos sociais que integre empregados, desempregados, trabalhadores precarizados ou terceirizados, o que implica a busca da cidadania plena e não apenas formal, pautada pelo ideário liberal para além da empresa, e a busca de uma nova sociabilidade, capaz de resistir à fome, à miséria e ao desemprego, construindo, desse modo, um projeto contrário à hegemonia da empresa e revitalizando a identidade de classe, capaz de unir as forças locais, regionais, nacionais e internacionais, de forma a oferecer à humanidade a possibilidade de uma vida cheia de sentido, para além do capital. 


\section{REFERENNCIAS}

ANTUNES, Ricardo. Dimensões da crise e as metamorfoses do mundo do trabalho. Revista Serviço Social G Sociedade, São Paulo, v. 17, n. 50, p. 78-132, abr. 1996.

. Reestruturação produtiva e desafios ao sindicalismo. Jornal PSTU, São Paulo, p. 11, 1999.

BECKER, Bertha K. Amazônia. São Paulo: Ática, 1994.

BORGES, Ângela; DRUCK, Maria da Graça. Crise global, terceirização e exclusão no mundo do trabalho. Caderno CRH 19, Salvador, n. 19, p. 2224, 1993.

BRAGA, Ruy et al. O fordismo e sua crise: elementos históricos e vertentes do debate atual. In: KATZ, C.; BRAGA, R. G.; COGGIOLA, O. L. A. Novas tecnologias: crítica da atual reestruturação produtiva. São Paulo: Xamã, 1995.

CARMO, Eunápio Dutra do. Gestão do trabalho na indústria do alumínio - Albras: noção de qualidade e seus interlocutores. Dissertação (Mestrado em Planejamento do Desenvolvimento) - Núcleo de Altos Estudos Amazônicos, Universidade Federal do Pará, Belém, 1997.

CASTRO, Edna Ramos de. Industrialização, transformações sociais e mercado de trabalho. In: CASTRO, Edna R.; MOURA, Edila; MAIA, Maria Lúcia Sá. Industrialização e os Grandes Projetos: desorganização do espaço. Belém: UFPA, 1995a. p.91-120.

- Organização do trabalho e recomposição do campo político em empresa com capital japonês na siderurgia. 1995b.

. Reestruturação produtiva e mercado de trabalho. Belém: UFPA, 1998 (Paper NAEA, 83).

CHRISTOPHE, Dejours et al. Psicodinâmica do trabalho: contribuições da escola dejouriana à análise da relação prazer, sofrimento e trabalho. São Paulo: Atlas, 1994.

COUTROT, Thomas. Critique de l'organisation du travail. Paris: La Découverte, 1999 (Coll. Repères).

DEDECCA, Cláudio Salvadori. Racionalização econômica e heterogeneidade nas relações e nos mercados de trabalho no capitalismo avançado. In: OLIVEIRA, Eduardo Barbosa de; MATTOSO, Eduardo Levi (Org.). Crise e trabalho no Brasil: modernidade ou volta ao passado. São Paulo: Scritta, 1996. 
DURKHEIN, Emile. A divisão do trabalho social. Lisboa: Presença, 1978. HARVEY, David. Condição pós-moderna. São Paulo: Companhia das Letras, 1995.

LIMA, Luís Flávio Maia. Integração regional e "enclaves fordistas" no Pará: uma abordagem geral. In: XIMENES, Tereza (Org). Cenários da industrialização na Amazônia. Belém: UNAMAZ/ UFPA/ NAEA, 1995. p. 105-156.

LIPIETZ, Alain. Audácia: uma alternativa para o século 21. São Paulo: Nobel, 1991.

LÔBO, Marco Aurélio Arbage. Estado e capital transnacional na Amazônia: o caso da Albras - Alunorte. Belém: UFPA/NAEA, 1996.

LÖWY, Michael. Em busca da alternativa social. Revista Praga: Estudos Marxistas, São Paulo, v. 8, p. 139-140, ago. 1999.

MARX, Karl. O capital. 12. ed. Rio de Janeiro: Bertrand Brasil S.A., 1989, v. 2.

MARX, Karl; ENGELS, Friedrich. A ideologia alemã: teses sobre Feuerbach. São Paulo: Moraes, 1984.

MOTA, Ana Elizabete. A cidadania do fordismo. História G Perspectiva, Uberlândia, p. 75-83, 1991.

OLIVEIRA, Francisco de. Economia da dependência imperfeita. Rio de Janeiro, Ed. Graal, 1984.

PINTO, Lúcio Flávio Pinto. Amazônia: o século perdido. Belém: Editora Jornal Pessoal, 1997.

RAMALHO, José Ricardo. Precarização do trabalho e impasses da organização coletiva no Brasil. In: ANTUNES, Ricardo et al. (Org). Neoliberalismo, trabalho e sindicatos: reestruturação produtiva no Brasil e na Inglaterra. São Paulo: Boitempo, 1997.

SMITH, Adam. A riqueza das nações. Rio de Janeiro: Abril cultural, 1982. 